\title{
Características químicas do solo sob sistema agroflorestal e floresta primária no município de Pacajá, Pará, Brasil
}

O artigo avalia e compara os atributos químicos do solo sob sistema agroflorestal (SAF) e floresta primária (FP) em diferentes profundidades e declividades no período chuvoso. O estudo foi realizado na Fazenda São Francisco, município de Pacajá, estado do Pará. Utilizou-se delineamento experimental inteiramente casualizado (DIC), com arranjo fatorial ( $2 \times 2 \times 2)$, sendo os tratamentos: sistema agroflorestal ( 5 anos) e floresta primária; profundidades (0-20 e 20-40 $\mathrm{cm}$ ); declividades média-alta e média-baixa (MA e MB). A área experimental consistiu de $320 \mathrm{~m} 2$ para cada tratamento, compostos por quatro repetições, cada uma de $80 \mathrm{~m} 2$. Amostras de solos foram coletadas com auxílio de trado holandês nas profundidades de 0-20 e $20-40 \mathrm{~cm}$, nas duas declividades no mês de janeiro, período das chuvas na região. Foram avaliados e comparados os atributos químicos: $\mathrm{pH}$ em água, carbono orgânico, $\mathrm{P}, \mathrm{K}, \mathrm{Ca}, \mathrm{Mg}$, Al, acidez potencial ( $\mathrm{H}+\mathrm{Al})$, soma de base (SB), capacidade de troca catiônica (CTC), porcentagem de saturação por bases (V\%). Constatou-se que as elevações da fertilidade do solo no SAF, em relação ao sistema de floresta primária, foram significativas. Os valores encontrados de pH no SAF foram satisfatórios. Os teores de carbono orgânico foram considerados altos no SAF e variaram de médio a alto na floresta primária (FP). Os teores de Al trocável no SAF foram baixos. O SAF apresentou melhorias na fertilidade do solo em relação à FP, mostrando maiores valores para o $\mathrm{P}$ na profundidade $0-20$ nas declividades MA e MB; $\mathrm{Ca}$ e Mg em ambas profundidades. Os teores de $\mathrm{K}$ no SAF se mostraram tão eficientes quanto na FP. A CTC dos solos em análise variou de média a alta, indicando que possuem uma boa capacidade para reter nutrientes. A saturação por bases (V\%) comprovou que os solos no SAF são caracterizados, predominantemente, como eutróficos.

Palavras-chave: Agroecossistemas; Qualidade do solo; Amazônia.

\section{Soil chemical characteristics under agroforestry system and primary forest in Pacajá city, Pará, Brazil}

\begin{abstract}
The article evaluates and compares soil chemical attributes under the agroforestry system (SAF) and primary forest (FP) at different depths and slopes in the rainy season. The study was carried out at Fazenda São Francisco, Pacajá municipality, Pará state. A completely randomized experimental design was used, with a factorial arrangement $(2 \times 2 \times 2)$. The treatments were: agroforestry system ( 5 years) and primary forest, depths $(0-20$ and $20-40 \mathrm{~cm})$ and, medium-high and mediumlow slopes (MA and MB). The experimental area consisted of $320 \mathrm{~m} 2$ for each treatment, composed of four replicates, each of $80 \mathrm{~m} 2$. Soil samples were collected with the aid of a Dutch auger at depths of 0-20 and 20-40 cm, on both slopes in January, the rainy season in the region. The chemical attributes were evaluated and compared: $\mathrm{pH}$ in water, organic carbon, $\mathrm{P}, \mathrm{K}, \mathrm{Ca}, \mathrm{Mg}, \mathrm{Al}$, potential acidity $(\mathrm{H}+\mathrm{Al})$, base sum $(\mathrm{SB})$, cation exchange capacity (CTC), percentage of base saturation (V\%). It was found that the elevations of soil fertility in the SAF compared to the primary forest system were significant. The pH values found in the SAF were satisfactory. Organic carbon levels were considered high in the SAF and varied from medium to high in the primary forest (FP). Exchangeable AI levels in the SAF were low. The SAF showed improvements in soil fertility compared to the FP, showing higher values for $\mathrm{P}$ at depths $0-20$ in the slopes MA and MB; Ca and Mg at both depths. $\mathrm{K}$ levels in SAF proved to be as efficient as in FP. Soils' CTC under analysis varied from medium to high, indicating that they have a good capacity to retain nutrients. V\% proved that the soils in the SAF are characterized, predominantly, as eutrophic.
\end{abstract}

Keywords: Agroecosystems; Soil quality; Amazon.

Topic: Ciências do Solo

Reviewed anonymously in the process of blind peer

Andréia de Freitas Soares (iD

Universidade Federal do Pará, Brasil

http://lattes.cnpq.br/3199399923771079

http://orcid.org/0000-0002-6516-7034

contato.andreia36@gmail.com

Sandra Andréa Santos da Silva (iD)

Universidade Federal do Pará, Brasil

http://lattes.cnpq.br/5742329435239170

http://orcid.org/0000-0002-1742-1544

sandrasilva@ufpa.br

José Farias Costa (iD

Universidade Federal do Pará, Brasil

http://lattes.cnpq.br/5597159666625051

http://orcid.org/0000-0002-2476-6743

josecosta.15@hotmail.com

DOI: 10.6008/CBPC2179-6858.2021.006.0004
Received: 08/06/2021

Approved: 24/06/2021

\author{
Vivian Dielly da Silva Farias (iD \\ Universidade Federal do Pará, Brasil \\ http://lattes.cnpq.br/0775979770122595 \\ http://orcid.org/0000-0003-0395-7839 \\ vivianfarias@ufpa.br \\ Amanda da Silva Nogueira (iD) \\ Universidade Federal Rural da Amazônia, Brasil \\ http://lattes.cnpq.br/2308304283885006 \\ http://orcid.org/0000-0002-1369-9549 \\ amandanogueira26@hotmail.com \\ Marcos Antônio Souza dos Santos (it \\ Universidade Federal Rural da Amazônia, Brasil \\ http://lattes.cnpq.br/1517009704490133 \\ http://orcid.org/0000-0003-1028-1515 \\ marcos.marituba@gmail.com
}

\section{Referencing this:}

SOARES, A. F.; SILVA, S. A. S.; COSTA, J. F.; FARIAS, V. D. S.; NOGUEIRA, A. S.; SANTOS, M. A. S.. Características químicas do solo sob sistema agroflorestal e floresta primária no município de Pacajá, Pará, Brasil. Revista Ibero Americana de Ciências Ambientais, v.12, n.6, p.45-59, 2021. DOI: http://doi.org/10.6008/CBPC2179-6858.2021.006.0004 


\section{INTRODUÇÃO}

O conceito de fertilidade do solo surgiu antes mesmo do entendimento do próprio solo e está relacionado ao desenvolvimento da humanidade, desde a antiguidade quando o ser humano passou a depender do cultivo da terra (ANGHINONI et al., 2013). Segundo o conceito mineralista vigente a fertilidade é definida como a habilidade do solo em fornecer nutrientes essenciais, em quantidades e proporções, adequados ao crescimento das plantas (CURY et al., 1993).

O solo é o meio principal para o crescimento das plantas, é uma camada de material biologicamente ativo, resultante de transformações complexas que envolvem o intemperismo de rochas e minerais, a ciclagem de nutrientes, a produção e a decomposição de biomassa (LOPES et al., 2007). Uma boa condição de funcionamento do solo é fundamental para garantir a capacidade produtiva dos agroecossistemas.

A importância da cobertura vegetal como elemento físico do agroecossistema se relaciona à proteção do solo e dos recursos hídricos e a proteção das áreas cultivadas como barreiras de proteção, contribuindo para o bem estar das comunidades, amenizando as condições de temperatura, umidade, fluxo de água e energia (LIMA, 1998).

Em condições naturais, o solo mantém-se em equilíbrio dinâmico com os fatores do ambiente. Sob essa condição, desenvolve-se a vegetação natural cuja qualidade e exuberância dependem da intensidade de ação de cada um dos fatores de formação do solo (CASSSOL et al., 2007).

Um solo fértil contém quantidades suficientes e balanceadas de todos os nutrientes essenciais em forma assimilável, deve estar razoavelmente livre de materiais tóxicos e possuir propriedades físicas e químicas que atendam a demanda dos vegetais. Um solo produtivo é aquele que, sendo fértil, deve estar localizado numa zona climática capaz de proporcionar suficiente umidade, nutriente e estrutura para o melhor desenvolvimento das raízes e das espécies nele cultivadas (RONQUIM, 2010).

Quando a vegetação natural sofre interferência de natureza antrópica, em virtude do estabelecimento de sistemas agrícolas produtivos, ocorre rompimento dos ciclos naturais. Este pode ser efêmero ou definitivo, dependendo da intensidade e do tipo de interferência. Por tanto a conservação do solo visa manter ou restabelecer o equilíbrio dinâmico do sistema solo sobre interferência antrópica (CASSSOL et al., 2007).

A avaliação das características químicas do solo é necessária para determinação da qualidade do aporte orgânico e da disponibilidade de nutrientes (SILVA et al., 2011). Um solo equilibrado proporciona à planta um desenvolvimento vigoroso e oferece condições para expressar todo seu potencial genético de produção.

Os atributos químicos do solo são largamente explorados na literatura e muito citados como indicativos de sua fertilidade. A avaliação da fertilidade dos solos tem sido uma ferramenta cada vez mais útil para aferir a capacidade dos sistemas agroflorestais, sendo assim, pode informar a respeito da importância da biodiversidade na manutenção dos solos, fornecendo informações à adequação das recomendações de adubação e manejo, de modo a aumentar a rentabilidade do produtor, assim como a sustentabilidade 
ambiental.

Existe um crescente interesse no estudo do comportamento dos solos quanto à sua capacidade de armazenar carbono e nutrientes, em resposta às diversas condições de manejo adotadas. A avaliação dessas mudanças auxilia a compreensão das alterações no ambiente que foram implantados os sistemas agroflorestais, contribuindo para o planejamento do manejo (MAFRA et al., 2008).

A utilização de SAF's pode ser uma alternativa viável e promissora, pois a utilização de culturas agrícolas juntamente com plantios de espécies nativas oferece um rendimento aos agricultores, amortizando os custos de implantação do reflorestamento, oferecendo uma renda extra com os produtos obtidos ao longo dos anos e uma melhor proteção do solo com uma cobertura mais rápida e eficiente (ABDO et al., 2008).

No sistema solo-planta, os nutrientes estão em estado de transferência contínuo e dinâmico, em que as plantas retiram os nutrientes do solo e os usam nos seus processos metabólicos, retornando-os para o solo naturalmente como liteira (CORRÊA et al., 2006). A fragilidade de um ecossistema pode ser entendida como o balanço de nutrientes e sua quantidade, destacando-se a eficácia da ciclagem, sendo às vezes necessário a adubação ser utilizada para manter ou elevar a produtividade do sistema (CAMPOS et al., 2009).

Estudos sobre os mais diferentes arranjos de sistemas agroflorestais tem apresentado destaque como modalidade sustentável de uso e manejo dos recursos naturais, levando vantagem em relação aos monocultivos. Este trabalho visa contribuir para um maior conhecimento da interação dos atributos químicos do solo disponível dentro do sistema agroflorestal encontrado na área de estudo. Deste modo seu objetivo foi avaliar e comparar os atributos químicos do solo sob o sistema agroflorestal e floresta primária em diferentes profundidades e declividades no período chuvoso, na Fazenda São Francisco, no município de Pacajá, estado do Pará.

\section{METODOLOGIA}

\section{Área de estudo}

As áreas de estudo estão localizadas na Fazenda São Francisco, propriedade rural com área total de aproximadamente 3 mil hectares, com a coordenada geográfica $\left(50^{\circ} 56^{\prime} 36,66^{\prime \prime} \mathrm{W}\right.$ e $\left.03^{\circ} 45^{\prime} 56,47^{\prime \prime} \mathrm{S}\right)$, localizada a 38km da sede do município de Pacajá, estado do Pará, cuja sede municipal está localizada geograficamente nas coordenadas $03^{\circ} 50^{\prime} 30^{\prime \prime}$ de latitude Sul e $50^{\circ} 38^{\prime} 35^{\prime \prime}$ de longitude oeste de Greenwich, estando a uma altitude aproximada de 105 metros (IDESP, 2012). O município de Pacajá foi fundado em 1988 com a construção da BR 230 (rodovia Transamazônica), situando-se na Mesorregião do Sudoeste Paraense e na Microrregião de Altamira.

O experimento foi instalado na Fazenda São Francisco, e o SAF em estudo apresentou-se com cinco anos idade, a sucessão do sistema agroflorestal ocorreu a partir do enriquecimento da vegetação secundária com espécies florestais e frutíferas, sendo o preparo da área mecanizada, na qual foram realizados tratos culturais, como capinas, adubação orgânica, sem qualquer tipo de manutenção do solo, seja correção de acidez ou aplicação de adubos químicos. 
$\mathrm{Na}$ área do SAF em estudo as espécies encontradas foram: Banana (Musa ssp.); Cacau (Theobroma cacao L.); Embaúba (Cecropia pachystachya); Gameleira (Ficus adhatodifolia Schott ex Spreng.); Ingá (Inga Edulis); Mamão (Carica papaya L.); Mamuí (Ocotea Bacellensis); Paricá (Schizolobium amazonicum Huber); Piriquiteira (Trema micrantha); Sumaúma (Ceiba pentandra Gaertn.); Tatájuba (Bagassa guianensis Aubl.) e Teca (Tectona grandis L. f.). A banana foi introduzida como sombreamento provisório da cultura do cacau, sendo este a principal cultura de interesse econômico do produtor, estabelecidos na mesma fileira com espaçamento 3,0 x 3,0m, as demais espécies foram implantadas aleatoriamente dentro do sistema, sendo que algumas espécies brotaram espontaneamente. A floresta primária em pesquisa caracteriza-se por ser de uma área de vegetação nativa, sem qualquer perturbação antrópica direta, com vegetação típica de terra firme.

\section{Características edafoclimáticas}

As características climáticas do município de Pacajá correspondem ao clima tropical úmido Af, de acordo com a classificação de Köppen-Geiger, apresentando temperatura mínima de $21^{\circ} \mathrm{C}$ e máxima de $32^{\circ} \mathrm{C}$, umidade relativa do ar de 85 a 90\% e índice de pluviosidade anual de $2.300 \mathrm{~mm}$. A precipitação pluviométrica é mais frequente entre os meses de fevereiro a abril, chegando a $350 \mathrm{~mm}$ no mês de abril e entre os meses de agosto a outubro, período mais seco, este valor cai para $70 \mathrm{~mm}$ no mês de outubro (IDESP, 2012).

Os solos predominantes no município de Pacajá estão em associações nas seguintes classes de solos: Podzólico Vermelho-Amarelo, textura argilosa; Podzólico Vermelho-Amarelo Plíntico, textura argilosa; Latossolo-Amarelo distrófico, textura argilosa, relevo suave ondulado e ondulado; Latossolo VermelhoAmarelo distrófico, textura argilosa; e Podzólico Vermelho-Amarelo distrófico, textura argilosa, relevo ondulado e forte ondulado (IDESP, 2012).

\section{Características da Floresta}

Predomina no município de Pacajá a Floresta de Terra Firme, de acordo com as variações de relevo e solo, nos seguintes subtipos: Floresta Densa dos Platôs, pequena ocorrência a noroeste do município; Floresta Densa Submontana, na superfície arrasada da serra de Carajás; Floresta Densa dos Vales, ao longo dos cursos d'água; Floresta Aberta Latifoliada cipoal, nas encostas das colinas e outeiros, e Floresta Aberta Mista cocal nos topos aplainados do relevo residual (IDESP, 2012).

\section{Tratamento e delineamento experimental}

O delineamento experimental foi inteiramente casualizado (DIC), com arranjo fatorial $(2 \times 2 \times 2)$, sendo os tratamentos: sistema agroflorestal (5 anos) e floresta primária; profundidades (0-20 e $20-40 \mathrm{~cm})$ e declividades (MA e MB).

\section{Coleta das amostras de Solos}

As coletas foram realizadas em janeiro de 2013, correspondendo o período chuvoso na região. A área 
experimental consistiu de $320 \mathrm{~m}^{2}$ para cada tratamento, composto por quatro repetições, cada uma medindo $80 \mathrm{~m}^{2}$. As amostras foram coletadas com auxílio de trado holandês nas profundidades de 0-20 e 20-40 cm e, em cada repetição, foram coletadas três amostras simples do solo para formar uma amostra composta, perfazendo um total de 16 unidades experimentais, sendo estas coletadas em duas declividades, classificadas como média-alta (MA) e média-baixa (MB).

As amostras de solo foram acondicionadas em sacos plásticos devidamente identificados, posteriormente foram protocolados e enviados ao laboratório de solos da Universidade Federal Rural de Amazônia (UFRA) para a realização das análises químicas. Em seguida foram analisadas pelos seguintes métodos propostos pela Embrapa (EMBRAPA, 2009). A determinação do carbono orgânico foi realizada por meio do método de Walkley-Black, e para o pH o método do potenciômetro (em água), os teores de $\mathrm{P}, \mathrm{K}, \mathrm{Ca}$ e Mg foram determinados pelo extrator Mehlich-1. Com base nos resultados das análises químicas, foi calculada a soma de base (SB), a capacidade de troca catiônica (CTC) e a saturação por bases (V\%).

O cálculo da matéria orgânica do solo, considerou o carbono orgânico representando, em média, $56 \%$ da $\mathrm{MO}$, com fator de equivalência igual a 1,724, entre esses dois atributos. Estes atributos foram analisados em duplicata, com obtenção da média para cada tratamento amostral.

\section{Análise estatística}

Os resultados das análises de fertilidade do solo foram submetidos à análise de variância, utilizando o programa estatístico BIOESTAT 5.3. Os dados obtidos nos SAF e floresta primária foram avaliados através de comparações entre esses dois sistemas, em diferentes profundidades e declividades entre si pelo teste fatorial a $95 \%$ de intervalo de confiança e $5 \%$ de probabilidade de erro.

\section{RESULTADOS E DISCUSSÃO}

Os parâmetros avaliados para cada tratamento foram: $\mathrm{pH}$, Corg, $\mathrm{P}, \mathrm{K}, \mathrm{Ca}, \mathrm{Mg}, \mathrm{Al}, \mathrm{H}+\mathrm{Al}, \mathrm{SB}, \mathrm{CTC}, \mathrm{V} \%$. Os resultados apresentados nas próximas seções estão descritos e dispostos nas tabelas comparando os sistemas: SAF e Floresta primária, nas duas profundidades $(0-20 \mathrm{~cm}$ e $20-40 \mathrm{~cm})$ e declividades: média-alta e média-baixa (MA e MB).

\section{Potencial Hidrogeniônico (pH)}

Os valores médios de $\mathrm{pH}$ do solo mostram que houve diferença significativa entre os tratamentos, em ambas as profundidades. Na camada de 0-20 cm, as declividades média-alta (MA) e média-baixa (MB) diferem entre si. No entanto, na profundidade $20-40 \mathrm{~cm}$, as declividades não diferem estatisticamente nos tratamentos (Tabela 1).

Resultados semelhantes foram encontrados por Barreto et al. (2006), com valores de 5,01; 4,50 para SAF e Floresta, respectivamente, em que os autores confirmam que os solos sob mata geralmente apresentam menores valores de $\mathrm{pH}$, pois a mineralização da matéria orgânica e os exsudatos ácidos liberados pelas raízes das plantas contribuem para aumentar a acidez do solo. Silva (2003) ressalva que é frequente 
encontrar resultados entre 4 e 6,5 nos solos da Amazônia.

Tabela 1: Média dos valores de potencial hidrogeniônico $(\mathrm{pH})$ em água em diferentes tratamentos, profundidades e declividades, na Fazenda São Francisco, Pacajá-PA.

\begin{tabular}{llll}
\hline & \multicolumn{3}{c}{$\mathbf{p H}$} \\
\cline { 2 - 4 } TRATAMENTO & $\mathbf{0 - 2 0 \mathbf { c m }}$ & $\mathbf{2 0 - 4 0 \mathbf { c m }}$ \\
\cline { 2 - 4 } & $\mathbf{M A}$ & $\mathbf{M B}$ & $\mathbf{M A}$ \\
\hline SAF & $5,98 \mathrm{Ab}$ & $6,49 \mathrm{Aa}$ & $\mathbf{M B}$ \\
FLORESTA & $4,24 \mathrm{Bb}$ & $\mathrm{Aa}$ & $6,21 \mathrm{Aa}$ \\
\hline
\end{tabular}

Médias seguidas de letras distintas (maiúscula na coluna e minúscula na linha) diferem estatisticamente pelo teste fatorial ao nível de $5 \%$ de probabilidade.

De acordo com Meurer (2007), o pH do solo na faixa de 5,5 a 6,5 é favorável ao crescimento da maioria das culturas, valores abaixo afetam a disponibilidade dos nutrientes para as plantas e favorece a absorção do alumínio, elemento tóxico que apresenta efeito prejudicial ao crescimento das plantas. Entretanto Brady et al. (2013) indicam que a amplitude de pH de 5,5 a 7,0 pode proporcionar um nível satisfatório de nutrientes às plantas. Pode-se perceber que os valores encontrados no SAF em estudo estão dentro dessas faixas favoráveis.

Tomé Junior (1997) faz referência aos valores de pH no solo abaixo de 4,5 ou acima de 7,5. Essas faixas indicam condições desfavoráveis às plantas, como pobreza de $\mathrm{Ca}$ e $\mathrm{Mg}$, altos teores de alumínio e alta fixação de fósforo. Os valores encontrados na Floresta avaliada no experimento se encontram nesta faixa desfavorável.

De acordo com Barreto et al. (2006) esse comportamento do pH do solo da Floresta ser menor que o do SAF, não classifica os solos de mata como degradados nem de baixa fertilidade, todo o sistema funciona com base na ciclagem de nutrientes, a reserva de nutrientes está armazenada na espessa manta orgânica que a fornece para a vegetação gradativamente.

\section{Carbono Orgânico (CO)}

Os dados da Tabela 2 representam as médias encontradas para o Carbono Orgânico em diferentes declividades e profundidades entre os tratamentos de SAF e Floresta, os quais estatisticamente não demonstraram diferenças estatisticamente significativas.

Tabela 2: Média dos valores de Carbono Orgânico (CO) em diferentes tratamentos, declividade e profundidades, na Fazenda São Francisco, Pacajá-PA.

\begin{tabular}{lllll}
\hline CO $\left(\mathrm{g} \mathrm{kg}^{-1}\right)$ & \multicolumn{5}{l}{} \\
\cline { 2 - 5 } TRATAMENTO & $\mathbf{0 - 2 0} \mathbf{c m}$ & $\mathbf{2 0 - 4 0 \mathbf { c m }}$ \\
\cline { 2 - 5 } & $\mathbf{M A}$ & $\mathbf{M B}$ & $\mathbf{M A}$ & $\mathbf{M B}$ \\
\hline SAF & $31,17 \mathrm{Aa}$ & $18,25 \mathrm{Aa}$ & $17,11 \mathrm{Aa}$ & $15,39 \mathrm{Aa}$ \\
FLORESTA & $12,54 \mathrm{Aa}$ & $14,82 \mathrm{Aa}$ & $12,92 \mathrm{Aa}$ & $12,92 \mathrm{Aa}$ \\
\hline
\end{tabular}

Médias seguidas de letras distintas (maiúscula na coluna e minúscula na linha) diferem estatisticamente pelo teste fatorial ao nível de $5 \%$ de probabilidade.

Mafra et al. (2008) estudando as variações de carbono orgânico sob diferentes sistemas, verificaram maior teor de carbono orgânico do solo na floresta nativa, variando de 23 a $56 \mathrm{~g} \mathrm{~kg}^{-1}$ com maior concentração na primeira camada. Segundo os autores, a adição de material orgânico proveniente, principalmente, da serapilheira é responsável pelo acúmulo de carbono na camada superficial do solo, à medida que vai sendo 
humificada.

Os valores obtidos de CO nesta pesquisa variam de 15,39 a $31,17 \mathrm{~g} \mathrm{~kg}^{-1}$ no SAF e de 12,54 a $14,82 \mathrm{~g}$ $\mathrm{kg}^{-1}$ na floresta. Resultados encontrados por Iwata et al. (2010) trabalhando com a dinâmica do carbono em diferentes idades no SAF e comparando com floresta nativa, apresentaram comportamento similar, em que o SAF promoveu maior estoque de carbono orgânico, variando de 8,12 a 22,90 $\mathrm{g} \mathrm{kg}^{-1}$ no SAF e de 15,54 a $21,58 \mathrm{~g} \mathrm{~kg}^{-1}$ na floresta, ambos em período chuvoso, o qual justifica que o SAF pode ser considerado eficiente na conservação do carbono orgânico e na manutenção da fração labial da matéria orgânica, promovendo a qualidade do solo.

Marques et al. (2012) estudando as variações de carbono orgânico sob diferentes sistemas, também verificaram maior teor de carbono orgânico nas camadas superficiais do solo na declividade média-alta, obtendo valores de $41,0 \mathrm{~g} \mathrm{~kg}^{-1}$ no SAF e de $30,0 \mathrm{~g} \mathrm{~kg}^{-1}$ na Floresta na profundidade de 0-10 $\mathrm{cm}$.

Pode-se constatar que os teores de CO encontrado no SAF são considerados altos, maiores que $14 \mathrm{~g}$ $\mathrm{kg}^{-1}$, nas duas profundidades e declividades estudadas, já o teor encontrado na Floresta é considerado médio entre 9 a $14 \mathrm{~g} \mathrm{~kg}^{-1}$, no entanto, o teor na profundidade $0-20 \mathrm{~cm}$ na declividade média baixa foi considerado alto, segundo Tomé Junior (1997). Marques et al. (2012) afirmam que pequenas variações na textura, estrutura do solo e qualidade da liteira podem interferir no deslocamento do carbono, implicando diferenças de variações ao longo do perfil do solo.

Segundo Faria et al. (2008) as plantas são as principais responsáveis pela adição ao solo de compostos orgânicos primários sintetizados no processo de fotossíntese que, dependendo da quantidade de resíduos depositados no solo, poderá resultar em aumento no teor de carbono orgânico do solo.

\section{Fósforo (P)}

Os resultados mostram que os valores médios de fósforo apresentaram diferenças significativas na profundidade 0-20 cm e entre as declividades em ambos os tratamentos. No entanto entre os tratamentos na profundidade $20-40 \mathrm{~cm}$, os valores obtidos não diferem estatisticamente (Tabela 3).

Tabela 3: Média dos valores de fósforo $(P)$ em diferentes tratamentos, profundidades e declividades, na Fazenda São Francisco, Pacajá-PA.

\begin{tabular}{|c|c|c|c|c|}
\hline \multirow{3}{*}{ TRATAMENTO } & \multicolumn{4}{|c|}{$\mathbf{P}\left(\mathrm{mg} \mathrm{dm}^{-3}\right)$} \\
\hline & \multicolumn{2}{|l|}{$0-20 \mathrm{~cm}$} & \multicolumn{2}{|c|}{$20-40 \mathrm{~cm}$} \\
\hline & MA & MB & MA & MB \\
\hline SAF & $15,52 \mathrm{Aa}$ & $0,93 \mathrm{Ab}$ & $2,42 \mathrm{Aa}$ & $0,33 \mathrm{Ab}$ \\
\hline FLORESTA & 2,32 Ba & $2,27 \mathrm{Bb}$ & $0,93 \mathrm{Ab}$ & $1,07 \mathrm{Aa}$ \\
\hline
\end{tabular}

Médias seguidas de letras distintas (maiúscula na coluna e minúscula na linha) diferem estatisticamente pelo teste fatorial ao nível de $5 \%$ de probabilidade.

Silva Junior et al. (2012) avaliando os atributos químicos do solo sob conversão de floresta amazônica em diferentes sistemas também encontraram diferenças significativas de $P$, que apresentaram valores de 9,8 e 7,8 $\mathrm{mg} \mathrm{dm}^{-3}$ no SAF e 2,2 e 1,6 $\mathrm{mg} \mathrm{dm}^{-3}$ na Floresta. Brady et al. (2013) explicam que grandes quantidades de óxidos de Fe e Al, presentes em muitos solos, torna possível a fixação de grande quantidade de fósforo por intermédio dessa reação. 
Observa-se que o maior valor obtido de fósforo foi 15,52 $\mathrm{mg} \mathrm{dm}^{-3}$ encontrado no SAF, na declividade média-alta (MA), primeira camada do solo, sendo este valor superior as demais variáveis. Provavelmente esse elevado teor de fósforo seja devido ao aumento da matéria orgânica pelo acúmulo dos restos vegetais, como a casca do cacau deixado após sua colheita, no SAF. De acordo com Addiscott et al. (2000), a ausência de revolvimento e manutenção de resíduos culturais na superfície (serapilheira) contribui para o aumento dos teores de $\mathrm{P}$ no solo.

Pode-se constatar que os teores de fósforo diminuíram com a profundidade e declividade, sendo estes considerados baixos. Segundo Tomé Junior (1997) o teor de P disponível tende a diminuir acompanhando o teor de matéria orgânica, além disso, o fósforo é de baixa mobilidade. Esse comportamento é justificado por Brady et al. (2013) que afirmam que valores de pH na faixa de 6,0 a 7,0, contribui para a menor fixação do $P$, pode-se observar este comportamento no SAF analisado. Silva et al. (2011) ressaltam que a redução dos teores de fósforo disponível em profundidade também pode ser influenciada pela menor mobilidade relativa do fósforo e aumento do teor de argila.

\section{Potássio (K)}

Os dados da Tabela 4 mostram o comportamento do potássio no solo sob diferentes tratamentos, profundidades e declividades analisadas. Observa-se que não houve diferença significativa entre os mesmos.

Tabela 4: Média dos valores de potássio (K) em diferentes tratamentos, profundidades e declividades, na Fazenda São Francisco, Pacajá-PA.

\begin{tabular}{lllll}
\hline \multirow{2}{*}{ TRATAMENTO } & \multicolumn{4}{c}{$\mathbf{K}\left(\mathrm{cmol}_{c} \mathrm{dm}^{-3}\right)$} \\
\cline { 2 - 5 } & $\mathbf{0 - 2 0} \mathbf{c m}$ & & $\mathbf{2 0 - 4 0} \mathbf{c m}$ & $\mathbf{M B}$ \\
\cline { 2 - 5 } & $\mathbf{M A}$ & $\mathbf{M B}$ & $\mathbf{M A}$ & $0,21 \mathrm{Aa}$ \\
SAF & $0,44 \mathrm{Aa}$ & $0,31 \mathrm{Aa}$ & $0,29 \mathrm{Aa}$ & $0,46 \mathrm{Aa}$ \\
\hline
\end{tabular}

Médias seguidas de letras distintas (maiúscula na coluna e minúscula na linha) diferem estatisticamente pelo teste fatorial ao nível de $5 \%$ de probabilidade.

Silva (2011) avaliando os atributos químicos em latossolo amarelo sob SAF's e floresta secundária, também não encontrou diferenças significativas no $\mathrm{K}$, que apresentaram 0,031 e 0,040 $\mathrm{cmol}_{\mathrm{c}} \mathrm{dm}^{-3}$, sendo os mesmos menores do que os valores encontrados nesta pesquisa. De acordo com Brady et al. (2013) o K contido nos minerais primários e secundários é lentamente liberado por processos de intemperismo.

Pode-se observar que na primeira camada, o potássio tendeu a apresentar maiores valores de concentração deste nutriente, em pesquisa com diferentes culturas de cobertura, Silveira et al. (2010) constataram que a maior presença de resíduos culturais na superfície do solo pode ter propiciado o acúmulo de K na primeira camada do solo.

Analisando os valores dos tratamentos nas declividades e profundidades verificou-se que os teores de potássio no SAF, são considerados médios segundo Tomé Junior (1997) variando entre a faixa de 0,11 a

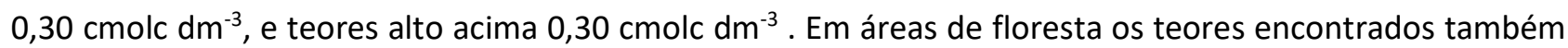
foram considerados médios. Este fato pode estar relacionado à maior concentração de ferro na solução do solo, que pode deslocar parte dos cátions que estão adsorvidos na fase sólida, aumentando sua 
disponibilidade para as plantas (VAHL, 1999).

Segundo Primavesi (2002) quando o nível de cálcio é suficientemente alto, um efeito positivo de potássio pode ser esperado. Vale ressaltar que os maiores valores de potássio encontrados no SAF, foram onde os teores de cálcio também foram elevados, confirmando o que está registrado na literatura. Dessa forma, fica evidente que o SAF em estudo se mostrou tão eficiente quanto à floresta primária, na ciclagem do potássio no solo.

\section{Cálcio (Ca)}

Os dados da Tabela 5 mostram a atuação do cálcio no solo sob diferentes profundidades e declividades nos tratamentos da pesquisa. Observa-se que houve diferença significativa entre os tratamentos nas duas profundidades estudadas de 0-20 e 20-40 cm. Já na declividade média-alta (MA) e média-baixa (MB) na profundidade de 0-20 cm não foram identificadas diferenças estatísticas para os tratamentos, no entanto houve diferença estatística entre as declividades quando observado a profundidade de $20-40 \mathrm{~cm}$ para ambos os sistemas.

Tabela 5: Média dos valores de cálcio (Ca) em diferentes tratamentos, profundidades e declividades, Fazenda São Francisco, Pacajá-PA.

\begin{tabular}{|c|c|c|c|c|}
\hline \multirow{3}{*}{ TRATAMENTO } & \multicolumn{4}{|c|}{$\mathrm{Ca}\left(\mathrm{cmol}_{\mathrm{C}} \mathrm{dm}^{-3}\right)$} \\
\hline & \multicolumn{2}{|l|}{$0-20 \mathrm{~cm}$} & \multicolumn{2}{|c|}{$20-40 \mathrm{~cm}$} \\
\hline & MA & MB & MA & MB \\
\hline SAF & $5,94 \mathrm{Aa}$ & 4,98Aa & $4,08 \mathrm{Ab}$ & $4,66 \mathrm{Aa}$ \\
\hline FLORESTA & 0,43 Ba & $0,54 \mathrm{Ba}$ & $0,27 \mathrm{Bb}$ & $0,43 \mathrm{Ba}$ \\
\hline
\end{tabular}

Médias seguidas de letras distintas (maiúscula na coluna e minúscula na linha) diferem estatisticamente pelo teste fatorial ao nível de $5 \%$ de probabilidade.

Na primeira camada 0-20 cm, os teores de cálcio foram maiores nas duas declividades, enquanto na camada mais profunda, nas duas declividades, os teores diminuíram. Silva (2011) também encontrou maiores valores de cálcio na primeira camada do solo, sendo estes em período chuvoso. Provavelmente, os maiores teores de Cálcio encontrados na época chuvosa, deveu-se a maior atividade dos microrganismos na decomposição da matéria orgânica e na solubilização de compostos minerais que contém cálcio, em função do maior teor de umidade do solo existente no período de maior precipitação pluvial (SANCHES et al., 1983; BESSHO et al., 1992).

Independente da declividade e profundidade os maiores teores de cálcio foram encontrados no SAF, considerados altos, maiores que $4,0 \mathrm{cmol}_{\mathrm{c}} \mathrm{dm}^{-3}$, já os teores na floresta foram considerados baixos, menores que 2,0 $\mathrm{cmol}_{\mathrm{c}} \mathrm{dm}^{-3}$ (TOMÉ JUNIOR, 1997). Na prática, os SAF's atendem a diversos objetivos, entre os quais, aumenta o teor de matéria orgânica e a diversificação da microbiota do solo, promovendo uma eficiente ciclagem de nutrientes (FERREIRA et al., 2004).

Segundo Barreto et al. (2006) os menores teores de cálcio na mata já são esperados, pois neste sistema o que está disponível no solo provavelmente esteja sendo absorvido pela vegetação, que por sua vez retorna para o solo novamente.

De acordo com Silva et al. (2011) esse aumento de cálcio se justifica pelo maior acúmulo de 
nutrientes na superfície do solo, decorrente da deposição de grande quantidade de resíduos provenientes da parte aérea das frutíferas e outras espécies vegetais componentes do SAF.

\section{Magnésio (Mg)}

Os dados da Tabela 6 mostram o comportamento do magnésio no solo sob diferentes profundidades e declividades nos tratamentos analisados. Observa-se que houve diferença significativa entre os tratamentos nas duas profundidades de 0-20 e $20-40 \mathrm{~cm}$. Já os valores obtidos nas declividades não diferem estatisticamente.

Tabela 6: Média dos valores de magnésio (Mg) em diferentes tratamentos, profundidades e declividades, na Fazenda São Francisco, Pacajá-PA.

\begin{tabular}{lllll}
\hline \multirow{2}{*}{ TRATAMENTO } & \multicolumn{4}{c}{$\mathbf{M g}\left(\mathrm{cmol}_{\mathrm{c}} \mathrm{dm}^{-3}\right)$} \\
\cline { 2 - 5 } & $\mathbf{0 - 2 0} \mathbf{c m}$ & $\mathbf{2 0 - 4 0 \mathbf { c m }}$ \\
\cline { 2 - 5 } & $\mathbf{M A}$ & $\mathbf{M B}$ & $\mathbf{M A}$ & $\mathbf{M B}$ \\
\hline SAF & $0,97 \mathrm{Aa}$ & $0,97 \mathrm{Aa}$ & $0,62 \mathrm{Aa}$ & $0,97 \mathrm{Aa}$ \\
FLORESTA & $0,43 \mathrm{Ba}$ & $0,31 \mathrm{Ba}$ & $0,12 \mathrm{Ba}$ & $0,27 \mathrm{Ba}$ \\
\hline
\end{tabular}

Médias seguidas de letras distintas (maiúscula na coluna e minúscula na linha) diferem estatisticamente pelo teste fatorial ao nível de $5 \%$ de probabilidade.

Pode-se observar que houve expressivo aumento de magnésio no SAF. Oliveira et al. (2006) estudando a qualidade dos solos em SAF's encontraram resultados aproximados ao desta pesquisa nas duas profundidades, com médias de 0,71 e 0,14 $\mathrm{cmol}_{\mathrm{c}} \mathrm{dm}^{-3}$. Brady et al. (2013) confirmam que o aumento deste nutriente pode estar associado à decomposição da matéria orgânica, favorecida pela melhoria das condições de fertilidade do solo.

Nota-se maior concentração de Mg na primeira camada do solo nas duas declividades, segundo Pavinato et al. (2008), o maior teor de Mg na camada superficial do solo, pode ser devido ao fato de que a adição de resíduos vegetais promovem o processo de humificação, a elevação do pH, em razão da acidez potencial com compostos de resíduos vegetais, deixando os cátions trocáveis $\mathrm{Ca}, \mathrm{Mg}$ e $\mathrm{K}$ mais livres em solução.

Independente da declividade e profundidade nos tratamentos, os maiores teores de magnésio estão no SAF, considerados médio entre 0,4 e $0,8 \mathrm{cmol}_{\mathrm{c}} \mathrm{dm}^{-3}$ e alto maiores que $0,8 \mathrm{cmol}_{\mathrm{c}} \mathrm{dm}^{-3}$, já os teores encontrado na floresta foram considerados baixo a médio, menores que $0,4 \mathrm{cmol}_{c} \mathrm{dm}^{-3}$ (TOMÉ JUNIOR, 1997).

\section{Alumínio (Al)}

Analisando os dados do alumínio no solo, verificou-se que houve diferenças significativas entre as profundidades e declividades nos tratamentos (Tabela 7).

Os dados obtidos se assemelham aos encontrados por Silva (2011), em que os teores de alumínio cresceram com a profundidade, variando de 0,59 a $1,18 \mathrm{cmol}_{c} \mathrm{dm}^{-3}$. Estudos realizados por Sena et al. (2007), em diferentes SAF's e floresta secundária, identificaram aumento dos teores de Al trocável, com o aumento da profundidade. Malavolta (1981) ratifica que no período chuvoso, as águas podem percolar o perfil, 
removendo grandes quantidades de cátions básicos, provocando o aumento da acidez ativa do solo, solubilizando os constituintes de $\mathrm{Al}$, liberando $\mathrm{Al}^{+3}$ que ocuparão as cargas negativas do complexo coloidal, aumentando a concentração do alumínio trocável.

Tabela 7: Média dos valores de alumínio (Al) em diferentes tratamentos, profundidades e declividades, na Fazenda São Francisco, Pacajá-PA.

\begin{tabular}{|c|c|c|c|c|}
\hline \multirow{3}{*}{ TRATAMENTO } & \multicolumn{4}{|c|}{ Al $\left(\mathrm{cmol}_{C} \mathrm{dm}^{-3}\right)$} \\
\hline & \multicolumn{2}{|l|}{$0-20 \mathrm{~cm}$} & \multicolumn{2}{|c|}{$20-40 \mathrm{~cm}$} \\
\hline & MA & MB & MA & MB \\
\hline SAF & $0,10 \mathrm{Ab}$ & $0,10 \mathrm{Aa}$ & $0,10 \mathrm{Ab}$ & $0,10 \mathrm{Aa}$ \\
\hline FLORESTA & 1,22 Ba & $0,78 \mathrm{Bb}$ & 1,27 Ba & $0,78 \mathrm{Bb}$ \\
\hline
\end{tabular}

Médias seguidas de letras distintas (maiúscula na coluna e minúscula na linha) diferem estatisticamente pelo teste fatorial ao nível de $5 \%$ de probabilidade.

Os maiores teores de alumínio foram encontrados em área de floresta, na declividade média-alta (MA) e nas profundidades 0-20 e 20-40 cm, respectivamente, de 1,22 e 1,27 $\mathrm{cmol}_{\mathrm{c}} \mathrm{dm}^{-3}$, da qual acompanhou a redução do pH nas camadas avaliadas, fato coerente com o observado por Silva Junior et al. (2012). Notase que o teor de Al permaneceu constante no SAF. Segundo Brady et al. (2013) a concentração de Al diminui quando os valores de pH estão acima de 5,5.

Segundo Primavesi (2002), o efeito tóxico do alumínio depende da proporção dos outros cátions e da sensibilidade da espécie, as culturas tropicais e subtropicais são comumente tolerantes ao alumínio trocável. Nota-se que os teores de alumínio encontrados no SAF, foram considerados baixos, menor que 0,5 $\mathrm{cmol}_{\mathrm{C}} \mathrm{dm}^{-3}$, sendo este um fator favorável a maioria das espécies tolerantes à toxidez do alumínio, já os teores encontrado na floresta foram considerados médios, entre 0,5 a $1,5 \mathrm{cmol}_{\mathrm{c}} \mathrm{dm}^{-3}$ (TOMÉ JUNIOR, 1997).

\section{Acidez Potencial (H+Al)}

Os resultados apresentados abaixo mostram a variação da concentração do íon hidrogênio associado ao íon alumínio, que configura a acidez potencial do solo, em diferentes tratamentos, profundidades e declividades.

Observa-se que não houve diferença estatística entre os tratamentos na profundidade de $0-20 \mathrm{~cm}$, nesta mesma camada, mas na declividade média-alta (MA) e média-baixa (MB) foi encontrada diferença significativa. Para a profundidade de $20-40 \mathrm{~cm}$, os resultados mostram que houve diferença significativa entre os tratamentos, no entanto nesta mesma camada, a declividade média-alta (MA) e média-baixa (MB) não difere estatisticamente em cada um dos tratamentos (Tabela 8).

Tabela 8: Média dos valores da acidez potencial ( $\mathrm{H}+\mathrm{Al}$ ) em diferentes tratamentos, profundidades e declividades, na Fazenda São Francisco, Pacajá-PA.

\begin{tabular}{|c|c|c|c|c|}
\hline \multirow{3}{*}{ TRATAMENTO } & \multicolumn{4}{|c|}{$\mathrm{H}+\mathrm{Al}\left(\mathrm{cmol}_{\mathrm{C}} \mathrm{dm}^{-3}\right)$} \\
\hline & \multicolumn{2}{|l|}{$0-20 \mathrm{~cm}$} & \multicolumn{2}{|c|}{$20-40 \mathrm{~cm}$} \\
\hline & MA & MB & MA & MB \\
\hline SAF & $8,70 \mathrm{Aa}$ & $4,04 \mathrm{Ab}$ & 4,32 Ba & $4,32 \mathrm{Ba}$ \\
\hline FLORESTA & $9,20 \mathrm{Aa}$ & $5,82 \mathrm{Ab}$ & 8,31 Aa & $5,95 \mathrm{Aa}$ \\
\hline
\end{tabular}

Médias seguidas de letras distintas (maiúscula na coluna e minúscula na linha) diferem estatisticamente pelo teste fatorial ao nível de $5 \%$ de probabilidade.

Os maiores valores de acidez potencial estão presentes na primeira camada do solo, na declividade 
média-alta (MA) tanto para o SAF quanto na floresta primária, apresentando valores de $8,70 \mathrm{cmol}_{\mathrm{c}} \mathrm{dm}^{-3} \mathrm{e}$ $9,20 \mathrm{cmol}_{\mathrm{c}} \mathrm{dm}^{-3}$, respectivamente. Oliveira et al. (2006) estudando a qualidade dos solos em SAF's encontraram valores que se assemelham variando de 6,30 a $7,06 \mathrm{cmol}_{c} \mathrm{dm}^{-3}$ no SAF e 6,73 a $9,10 \mathrm{cmol}_{c} \mathrm{dm}^{-3}$ na mata, o qual justifica a tendência de aumento da acidez potencial em áreas de floresta que é acompanhada pelos maiores teores de matéria orgânica.

Observa-se que na primeira camada superficial entre as declividades houve diferenças de acidez potencial. Segundo Malavolta (1981), Brady et al. (2013) isso se justifica pela decomposição de compostos orgânicos favorecendo o aumento da acidez potencial devido aos radicais carboxílicos e fenólicos presentes na matéria orgânica.

\section{Soma de Bases (SB)}

Na Tabela 9 os valores médios de soma de bases do solo apresentaram diferenças significativas nas duas profundidades entre os tratamentos e nas declividades na profundidade de $20-40 \mathrm{~cm}$ quando observados os tratamentos.

Tabela 9: Média dos valores da soma de base (SB) em diferentes tratamentos, profundidades e declividades, Fazenda São Francisco, Pacajá-PA.

\begin{tabular}{|c|c|c|c|c|}
\hline \multirow{3}{*}{ TRATAMENTO } & \multicolumn{4}{|c|}{ SB $\left(\mathrm{cmol}_{\mathrm{c}} \mathrm{dm}^{-3}\right)$} \\
\hline & \multicolumn{2}{|l|}{$0-20 \mathrm{~cm}$} & \multicolumn{2}{|c|}{$20-40 \mathrm{~cm}$} \\
\hline & MA & MB & MA & MB \\
\hline SAF & $7,35 \mathrm{Aa}$ & $6,26 A a$ & $4,99 \mathrm{Ab}$ & $5,84 \mathrm{Aa}$ \\
\hline FLORESTA & 1,11 Ba & $1,10 \mathrm{Ba}$ & $0,52 \mathrm{Bb}$ & $1,16 \mathrm{Ba}$ \\
\hline
\end{tabular}

Médias seguidas de letras distintas (maiúscula na coluna e minúscula na linha) diferem estatisticamente pelo teste fatorial ao nível de $5 \%$ de probabilidade.

Os valores da soma de bases variaram de 4,99 a 7,35 $\mathrm{cmol}_{\mathrm{c}} \mathrm{dm}^{-3}$ no SAF e de 0,52 a 1,16 $\mathrm{cmol}_{\mathrm{c}} \mathrm{dm}^{-3}$ no sistema Floresta, estudos sobre a qualidade dos solos realizados por Oliveira (2006), apontam valores entre 0,31 a 2,49 $\mathrm{cmol}_{\mathrm{c}} \mathrm{dm}^{-3}$ no $\mathrm{SAF}$, e valores de 0,09 a $2,58 \mathrm{cmol}_{\mathrm{c}} \mathrm{dm}^{-3}$ na floresta; estes valores são inferiores aos encontrados no SAF e relativamente superiores ao sistema floresta nesta pesquisa.

Silva et al. (2011) pesquisando diferentes SAF's e floresta encontraram valores compreendidos entre 0,9 a 4,0 $\mathrm{cmol}_{\mathrm{c}} \mathrm{dm}^{-3}$ no SAF e de 0,9 a 3,1 $\mathrm{cmol}_{\mathrm{c}} \mathrm{dm}^{-3}$ na floresta. Segundo estes autores os resultados observados em relação a soma de bases também estão relacionados com os altos teores de carbono orgânico, o que possibilita uma eficiente ciclagem de nutrientes. De acordo com Ribeiro et al. (1999) a soma de bases para o SAF, considerando as duas profundidades e declividades, são considerados de médio a alto, acima de $5 \mathrm{cmol}_{c} \mathrm{dm}^{-3}$.

\section{Capacidade de Troca Catiônica (CTC)}

Os dados desta pesquisa mostram que houve diferença significativa entre os tratamentos nas profundidades do solo, assim como diferem na profundidade de $0-20 \mathrm{~cm}$ as declividades média-alta (MA) e média- aixa (MB) em cada um dos tratamentos (Tabela 10). 
Tabela 10: Média dos valores da Capacidade de Troca Catiônica (CTC) em diferentes tratamentos, profundidades e declividades, na Fazenda São Francisco, Pacajá-PA.

\begin{tabular}{|c|c|c|c|c|}
\hline \multirow{3}{*}{ TRATAMENTO } & \multicolumn{4}{|c|}{ CTC $\left(\mathrm{cmol}_{\mathrm{c}} \mathrm{dm}^{-3}\right)$} \\
\hline & \multicolumn{2}{|l|}{$0-20 \mathrm{~cm}$} & \multicolumn{2}{|c|}{$20-40 \mathrm{~cm}$} \\
\hline & MA & MB & MA & MB \\
\hline SAF & $16,05 \mathrm{Aa}$ & $10,30 \mathrm{Ab}$ & $9,30 \mathrm{Aa}$ & $10,16 \mathrm{Aa}$ \\
\hline FLORESTA & $10,31 \mathrm{Ba}$ & $6,91 \mathrm{Bb}$ & $8,82 \mathrm{Ba}$ & $7,10 \mathrm{Ba}$ \\
\hline
\end{tabular}

Médias seguidas de letras distintas (maiúscula na coluna e minúscula na linha) diferem estatisticamente pelo teste fatorial ao nível de $5 \%$ de probabilidade.

A capacidade de troca de cátions (CTC) dos solos variou de 9,30 a $16,05 \mathrm{cmol}_{\mathrm{c}} \mathrm{dm}^{-3}$ no SAF e de 6,91 a 10,31 $\mathrm{cmol}_{\mathrm{c}} \mathrm{dm}^{-3}$ na floresta. Esses valores são superiores aos encontrados por Silva Junior et al. (2012), cujos resultados variaram de 4,58 e 5,33 $\mathrm{cmol}_{\mathrm{c}} \mathrm{dm}^{-3}$ no SAF e de 6,34 a $8,83 \mathrm{cmol}_{\mathrm{c}} \mathrm{dm}^{-3}$ na floresta, na qual os autores justificam a redução da capacidade de troca de cátions pela influência da acidez potencial.

Os dados obtidos nesta pesquisa são relativamente inferiores aos dos estudos realizados por Barreto et al. (2006) o qual mostra os valores de CTC variando de 11,90 a $15,92 \mathrm{cmol}_{\mathrm{c}} \mathrm{dm}^{-3}$ e 12,60 a $16,16 \mathrm{cmol}_{\mathrm{c}} \mathrm{dm}^{-}$ 3 , respectivamente, sob SAF e floresta. De acordo com Primavesi (2002) o aumento da capacidade de troca catiônica significa que a planta será mais bem nutrida, pois o solo conseguirá manter nutrientes em formas trocáveis e disponíveis para a planta.

Analisando o perfil do solo, pode-se constatar que a capacidade de troca catiônica diminui tanto na profundidade, quão gradativamente nas declividades nos tratamentos avaliados. Conforme Lopes et al. (2004), os solos com CTC entre 6 a $25 \mathrm{cmol}_{\mathrm{C}} \mathrm{dm}^{-3}$ apresentam alto teor de argila e alto teor de matéria orgânica; maior capacidade de retenção de nutrientes a uma certa profundidade. Pode-se constatar que os valores encontrados na pesquisa nos dois tratamentos estão compreendidos em meio a essas estimativas.

Constatou-se ainda que os valores de CTC no SAF e Floresta são considerados de médio a alto, respectivamente, sendo estes valores compreendidos entre 4,6 e $10 \mathrm{cmol}_{c} \mathrm{dm}^{-3}$ e acima de $10 \mathrm{cmol}_{c} \mathrm{dm}^{-3}$ (RIBEIRO et al., 1999).

Segundo Luchese et al. (2002) o percentual de argila e de matéria orgânica são atributos que determinam as propriedades químicas, físicas e biológicas de um solo, como a estrutura, capacidade de retenção de água, disponibilidade de nutrientes para as plantas e a capacidade de reter cátions, sendo seus teores de extrema importância para a manutenção da fertilidade desse solo.

\section{Saturação por Base (V\%)}

Os dados da Tabela 11 mostram que em relação à Saturação por Base no solo houve diferenças significativas entre as profundidades e declividades nos tratamentos.

Tabela 11: Média dos valores da Saturação por base (V\%) em diferentes tratamentos, profundidades e declividades, na Fazenda São Francisco, Pacajá-PA.

\begin{tabular}{lllll}
\hline \multirow{2}{*}{ TRATAMENTO } & \multicolumn{4}{c}{ V\% $\left(\mathrm{cmol}_{c} \mathrm{dm}^{-3}\right)$} \\
\cline { 2 - 5 } & $\mathbf{0 - 2 0} \mathbf{c m}$ & $\mathbf{2 0 - 4 0 \mathbf { c m }}$ \\
\cline { 2 - 5 } & MA & MB & MA & MB \\
\hline SAF & $45,71 \mathrm{Ab}$ & $60,76 \mathrm{Aa}$ & $53,58 \mathrm{Ab}$ & $57,44 \mathrm{Aa}$ \\
FLORESTA & $10,76 \mathrm{Bb}$ & $15,86 \mathrm{Ba}$ & $5,90 \mathrm{Bb}$ & $16,29 \mathrm{Ba}$ \\
\hline
\end{tabular}

Médias seguidas de letras distintas (maiúscula na coluna e minúscula na linha) diferem estatisticamente pelo teste fatorial ao nível de $5 \%$ de probabilidade. 
No SAF, os valores de saturação por base (V\%) indicaram uma condição eutrófica, enquanto que o sistema de floresta apresentou característica distrófica, exceto a camada de 0-20 cm, na declividade médiaIta no SAF, que apresenta valor inferior a 50\%, caracterizando como solo distrófico (SILVA, 2003).

Ferreira Junior et al. (2009) relatam que um perfil do solo com maior saturação por base é resultado de um satisfatório efeito da ciclagem dos nutrientes estabelecido na área, permitindo assim melhores condições de fertilidade.

Barreto et al. (2006) pesquisando características químicas entre SAF's e mata, encontraram no SAF valores de V\% aproximadamente três vezes superior ao sistema Mata Atlântica, indicando que a nutrição da vegetação na mata é sustentada, provavelmente, pela ciclagem de nutrientes, com grande acúmulo na manta orgânica.

\section{CONCLUSÕES}

Os solos com SAF's propiciam melhorias para a fertilidade do solo com redução da acidez e aumento nos teores de alguns nutrientes semelhantes aos ecossistemas de floresta nativa. Os valores encontrados de pH no SAF estão entre as faixas satisfatória para que haja disponibilidade de nutrientes para as plantas.

Os teores de K no SAF se mostraram tão eficiente quanto na floresta primária. Os teores de Al trocável foram baixos no SAF. A capacidade de troca catiônica (CTC) dos solos em estudo variou de médio a alto. A saturação por base (V\%) dos solos no SAF os caracterizam como solos eutróficos.

\section{REFERÊNCIAS}

ABDO, M. T. V. N.; VALERI, S. V.; MARTINS, A. L. M.. Sistemas Agroflorestais e Agricultura familiar: uma parceria interessante. Revista Tecnologia \& Inovação Agropecuária, São Paulo, p.50-59, 2008.

ADDISCOTT, T. M.; THOMAS, D.. Tillage, mineralization and leaching: phosphate. Soil Till. Res., v.53 p.255-273, 2000.

ANGHINONI, I.; CARVALHO, P. C. F.; COSTA, S. E. V. G. A. Abordagem sistêmica do solo em sistemas integrados de produção agrícola e pecuária no subtrópico Brasileiro. In: Tópicos em Ciência dos Solos. Viçosa, 2013. p.325-380.

BARRETO, A. C.; LIMA, F. H. C.; FREIRE, M. B. G. S.; ARAÚJO, Q. R.. Características químicas e físicas de um solo sob floresta, sistema agroflorestal e pastagem no sul da Bahia. Revista Caatinga, Mossoró, v.19, n.4, p.415-425, 2006.

BESSHO; T.; BELL, L. C.. Soil solid and solution phase changes and mung bean response during amelioration of aluminum toxicity with organic matter. Plant and Soil., v.140, n.2, p.183-196, 1992.

BRADY, N. C.; WEIL, R. R.. Elementos da natureza e propriedades dos Solos. 3 ed. Porto Alegre: Bookman, 2013.

CAMPOS, M. L.; MARCHI, G.; LIMA, D. M.; SILVA, C. A.. Ciclagem de nutrientes em floretas e pastagens. Boletim Agropecuário da Universidade Federal de Lavras, n.65, p.161, 2009.
CASSSOL, E. E.; DENARDIN, J. E.; KOCHHANN, R. A.. Sistema Plantio Direto: Evolução e implicações sobre a conservação do solo e da água. In: Tópicos em Ciência dos Solos. Viçosa: Sociedade Brasileira de Ciência do Solo, 2007. p.333-369.

CORRÊA, F. L. O.; RAMOS, J. D.; GAMA-RODRIGUES, A. C.; MULLER, M. W.. Produção de Serapilheira em Sistema Agroflorestal Multiestratificado no Estado de Rondônia, Brasil. Revista Ciência e Agrotecnologia, Lavras, v.30, n.6, p.1099-1105, 2006.

CURY, N.; LARACH, J. O. I.; KAMPF, N.; MUNIZ, A. C.; FONTES, L. E. F.. Vocabulário de ciência do solo. Campinas: Sociedade Brasileira de Ciência do Solo, 1993.

EMBRAPA. Empresa Brasileira de Pesquisa Agropecuária. Manual de análises químicas de solos, plantas e fertilizantes. 2 ed. Brasília: Embrapa Informação Tecnológica, 2009.

FARIA, G. E.; BARROS, N. F.; NOVAIS, R. F.; SILVA, I. R.; NEVES, J. C. L.. Carbono orgânico total e frações da matéria orgânica do solo em diferentes distâncias do tronco de eucalipto. Scientia Forestalis, Piracicaba, v.36, n.80, p.265277, 2008.

FERREIRA, C. P.; KATO, O. R.; COSTA, C. A. C.. Carbono orgânico, nitrogênio e a razão $\mathrm{C} / \mathrm{N}$ em solo sob sistemas agroflorestais no nordeste paraense. In: CONGRESSO BRASILEIRO DE SISTEMAS AGROFLORESTAIS, 5. Anais. Curitiba: EMBRAPA, 2004. 
FERREIRA JUNIOR, W. G.; SCHAEFER, C. E. G. R.; SILVA, F. S.. Uma visão Pedogeomorfológicasobre as formações florestais da Mata Atlântica. In: MARTINS, S. M.. Ecologia de Floresta tropicais do brasil. Viçosa, 2009. p.109-142.

IDESP. Instituto de Desenvolvimento Econômico Social e Ambiental do Pará. Estatística Municipal de Pacajá. Núcleo de disseminação da informação, comunicação e suporte de decisão. IDESP, 2012.

IWATA, B. F.; LEITE, L. F. C.; CAMPOS, L. P.; ARAÚJO, A. S. F.; COSTA, C. N.. Dinâmica Sazonal do Carbono orgânico total e da Biomassa Microbiana em Sistemas Agroflorestais e Agricultura de Corte e Queima no Cerrado Piauiense. In: FERTIBIO - REUNIÃO BRASILEIRA DE FERTILIDADE DO SOLO E NUTRIÇÃO DE PLANTAS, 29; REUNIÃO BRASILEIRA SOBRE MICORRIZAS, 13; SIMPÓSIO BRASILEIRO DE MICROBIOLOGIA DO SOLO, 11; REUNIÃO BRASILEIRA DE BIOLOGIA DO SOLO, 8. Anais. Guarapari, 2010.

LOPES, A. S.; GUILHERME, L. R. G.. Fertilidade do Solo e Produtividade Agrícola. In: NOVAIS, R. F.; ALVAREZ V, V. H.; BARROS, N. F.; FONTES, R. L. F.; CANTARUTTI, R. B.; NEVES, J. C. L.. Fertilidade do Solo. Viçosa: SBCS, 2007. p.01-64.

LUCHESE, E. B.; FAVERO, L. O. B.; LENZI, E.. Fundamentos da química no solo. 2 ed. Rio de Janeiro: Freitas Bastos, 2002.

MAFRA, A. L.; GUEDES, S. F. F.; FILHO, O. K.; SANTOS, J. C. P.; ALMEIDA, J. A.; ROSA, J. D.. Carbono Orgânico e Atributos químicos do solo em áreas florestais. Revista árvore, Viçosa, v.32, n.2, p.217-224, 2008.

MALAVOLTA, E.. Manual de Química Agrícola: Adubos e Adubação. 3 ed. São Paulo: Agronômica Ceres, 1981.

MARQUES, J. D. O.; LUIZÃO, F. J.; TEIXEIRA, W. G.; FERREIRA, S. J. F.. Variações do Carbono Orgânico Dissolvido e de Atributos Físicos do Solo Sob Diferentes Sistemas de Uso da Terra na Amazônia Central. Revista Brasileira de Solos, v.36, p.611-622, 2012.

MEURER, E. J.. Fatores que influenciam o crescimento e o desenvolvimento das plantas. In: NOVAES, R. F.; ALVAREZ, V. V. H.; BARROS, N. F.; FONTES, R. L. F.; CANTARUTTI, R. B.; NEVES, J. C. L.. Fertilidade do solo. Viçosa: SBCS, 2007. p.6590 .

OLIVEIRA, A. S.. Qualidade do solo em sistemas agroflorestais em Alta Floresta/MT. Dissertação (Mestrado) - Universidade Federal de Viçosa, Alta Floresta, 2006.

LIMA, W. P.. Função Hidrológica da mata ciliar. In: BARBOSA, L. M.. Simpósio sobre mata ciliar. Campinas: Fundação Cargill, 1998.

PAVINATO, P. S.; ROSOLEM, C. A.. Disponibilidade de nutrientes no solo: decomposição e liberação de compostos orgânicos de resíduos vegetais. Rev. Bras. de Ci. do Solo,
Viçosa, v.32, n.3, p.911-920, 2008.

PRIMAVESI, A.. Manejo ecológico do solo: a agricultura em regiões tropicais. São Paulo: Nobel, 2002.

RONQUIM, C. C.. Conceitos de fertilidade do solo e manejo adequado para as regiões tropicais. Campinas: Embrapa Monitoramento por Satélite, 2010

RIBEIRO, A. C.; GUIMARÃES, P. T. G.; ALVAREZ V. V. H.. Recomendação para o uso de corretivos e fertilizantes em Minas Gerais. 5 ed. Viçosa: Comissão de Fertilidade do Solo do Estado de Minas Gerais, 1999.

SANCHES, P. A.; VILLACHICA, J. H.; BANDY, D. E.. Soil fertility dynamics after clearing a tropical rainforest in Peru. Soil. Sci. Soc. Am. J., v.47, p.1171-1178, 1983.

SENA, W. L.; SILVA, J. L.; SILVA JUNIOR, M. L.. Avaliação de atributos químicos de um Latossolo Amarelo sob diferentes sistemas de uso da terra. Revista das Ciências Agrárias, n.48, p.25-40, 2007.

SILVA, S. B.. Análise de Solos. Serviço de Documentação e Informação. Universidade Federal Rural da Amazônia, 2003.

SILVA, I. R.; MENDONÇA, E. S.. Matéria orgânica do solo. In: NOVAIS, R. F.; ALVARES, V. V. H.; BARROS, N. F.; FONTES R. L. F. F.; CANTARUTII, R. B. C.; NEVES, J. C. L.. Fertilidade do solo. Viçosa, 2007. p.275-374.

SILVA, S. A. S.. Atributos químicos e microbiológicos em latossolo amarelo sob sistemas agroflorestais e floresta secundária em Bragança, Pará. Tese (Doutorado) Universidade federal Rural da Amazônia, Belém, 2011.

SILVA, D. C.; SILVA, M. L. N.; CURI, N.; OLIVEIRA, A. H.; SOUZA, F. S.; MARTINS, S. G.; MACEDO, R. L. G.. Atributos do solo em sistemas Agroflorestais, cultivo convencional e Floresta Nativa. Revista de Estudos Ambientais, v.13, n.1, p.77-86, 2011.

SILVA JUNIOR, C. A.; BOECHAT, C. L.; CARVALHO, L. A.. Atributos químicos do solo sob conversão de floresta amazônica para diferentes sistemas na região norte do Pará, Brasil. Bioscience Journal, Uberlândia, v.28, n.4, p.566-572, 2012.

SILVEIRA, P. M.; CUNHA, P. C. R.; STONE, L. F.; SANTOS, G. G.. Atributos químicos de solo cultivado com diferentes culturas de cobertura. Pesquisa Agropecuária Troical, Goiânia, v.40, n.3, p.283-290, 2010.

TOMÉ JUNIOR, J. B.. Manual para interpretação de análise de solo. Guaíba: Agropecuária, 1997.

VAHL, L. C.. Fertilidade de solos de várzeas. In: GOMES, A. S.; PAULETTO, E. A.. Manejo do solo e da água em áreas de várzeas. Pelotas: Embrapa Clima Temperado, 1999. p.119162.

A CBPC - Companhia Brasileira de Produção Científica (CNPJ: 11.221.422/0001-03) detém os direitos materiais desta publicação. Os direitos referem-se à publicação do trabalho em qualquer parte do mundo, incluindo os direitos às renovações, expansões e disseminações da contribuição, bem como outros direitos subsidiários. Todos os trabalhos publicados eletronicamente poderão posteriormente ser publicados em coletâneas impressas sob coordenação da Sustenere Publishing, da Companhia Brasileira de Produção Científica e seus parceiros autorizados. Os (as) autores (as) preservam os direitos autorais, mas não têm permissão para a publicação da contribuição em outro meio, impresso ou digital, em português ou em tradução. 